\title{
USING OF BIOETHANOL FUELS IN IC ENGINE ${ }^{1}$ F. Farkas, ${ }^{2}$ T. Molnár \\ ${ }^{1}$ University of Szeged, Faculty of Engineering, Mars sqr. 7., 6724, Szeged, Hungary e-mail: farkasf@mk.u-szeged.hu \\ ${ }^{2}$ University of Szeged, Faculty of Engineering, Mars sqr. 7., 6724, Szeged, Hungary e-mail: molnart@mk.u-szeged.hu
}

\begin{abstract}
Renewables - excluding large hydro accounted for $48 \%$ - increased to $15.2 \%$ of world cumulative generation capacity in 2014, from 13.8\% in 2013. In the EU, the European Parliament approved a reform of the 2020 biofuels target. The new version of the Renewable Energy Directive (RED) distributes the $10 \%$ cal. biofuels target into a share for cropbased biofuel (limited at 7\% cal.) with the rest to be met with another biofuels and renewable electricity containing multiple counting possibilities.[7] Merely $2 \%$ of the EU's fuel consumption can be covered by its own researches, which looks good pretend a strong dependence on the oil exporting countries. The implementations of biogenic fuels produced from fast growing plant is continuously gaining in importance with regard to economic and environmental effects. Generally they are not offered in their pure form but just as blend components to conventional fuels. [1][3][4] Their mixtures can bring about fundamental feature improvements.[2][5][6] Ethanol fuel output in 2015 reached a peak high helped by rising gasoline demand in the US. Besides, the changes in the fuel taxation in Brazil and an increase in the minimum blending ratio also pushed along the ethanol fuel demand. The weaker euro and low grain prices on the back of a record wheat crop turned into a considerable growth in output in the EU. Disregard the stimulating developments on the legislative side, it must also be confessed that the decreasing crude oil prices took their customs on the 2015 biofuel markets. For ethanol fuel, more growth could theoretically arrive from an extending of E-10 in EU member states. Unnecessary to discuss that an outlook for a post-2020 biofuels target at the EU level does not valid [8][9].
\end{abstract}

Keywords: renewable energies, biofuel target, blending ratio, ethanol fuel demand.

\section{INTRODUCTION}

In order to implement the objectives of research task the comparative analysis were made with two different manufacturer's bioethanol fuels (AGIP-E85, OIL-E85) in the engine testing brake. The measuring apparatus contains- a Honda GX 160 type (one cylinder, 4-stroke) gasoline engine, equipped with Energotest-MMP-4 type electric-brake and a computer based control and evaluating system connected to it.

\section{MATERIALS AND METHODS}

The test was based on three short-term runs operated with commercial gasoline (reference) and two different bioethanol fuels with the aim to compare the internal combustion engine behaviours by unchanged settings.

The engine test was made according to directives of ECE 24 standard, so the engine was fitted with the original intake and exhausting systems and these drove the moving parts. The measurements were made in 23 operating points between $1400 \mathrm{rpm}$ and $3600 \mathrm{rpm}$. The values of torque (M) and the effective power $\left(\mathrm{P}_{\text {eff }}\right)$ were measured in case of full throttle and fixed dispenser lever position in every operating point. After selecting a given operating point the control of the measurement, together with the collection and the evaluation of the data are completely automated. (Energopower Software by Energotest Ltd.) 


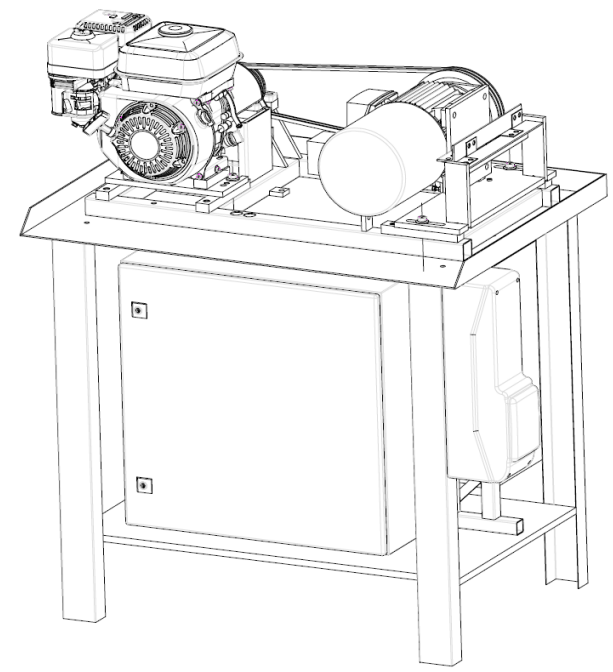

Figure 1" MMP-4 „Electric brake”

\section{RESULTS}

Deviations in the combustion behaviour and the functions of the engine control unit are quantifiable at the test bench. For the two bioethanol (E-85) fuels tested their torque and effective power parameters were more less than the reference E-95 values. Diagram 1 shows the relations between torque and revolution and the 2-nd one describes connections between effective power and rpm.

We established more less values in case of both parameters (less, than 50\%), which can explain with lower calorific value $(26.7 \mathrm{MJ} / \mathrm{kg}$ ) and stoichiometric ratio (8.97) of bioethanols oppposite gasoline' same parameters $(43 \mathrm{MJ} / \mathrm{kg}$ and 14.7$)$.

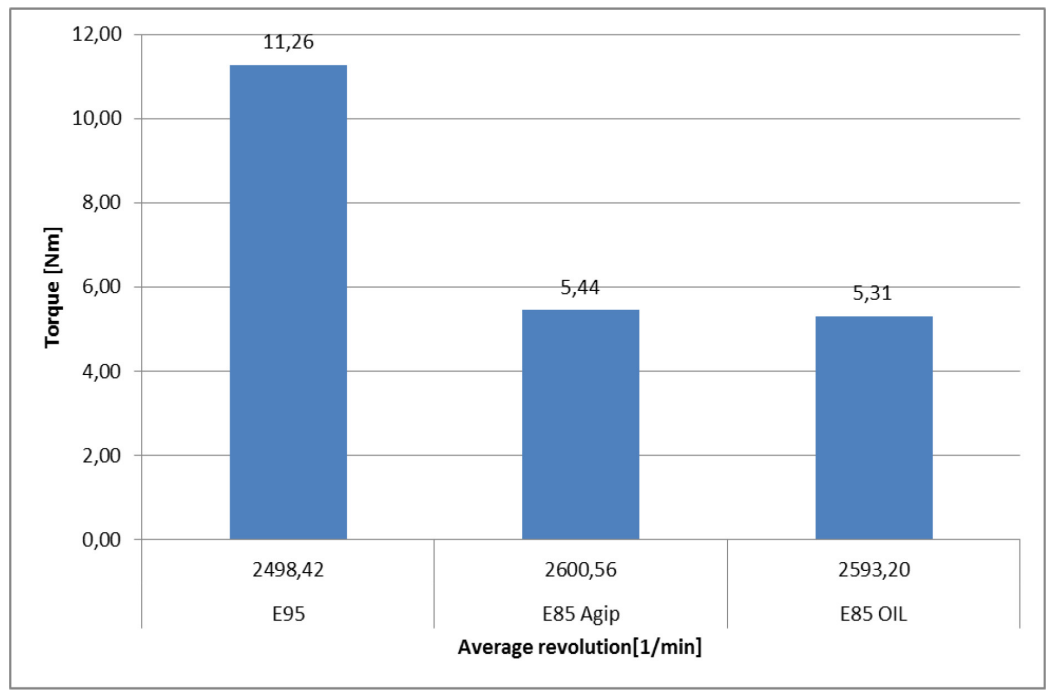

Figure 1. Relations between torque and revolution 


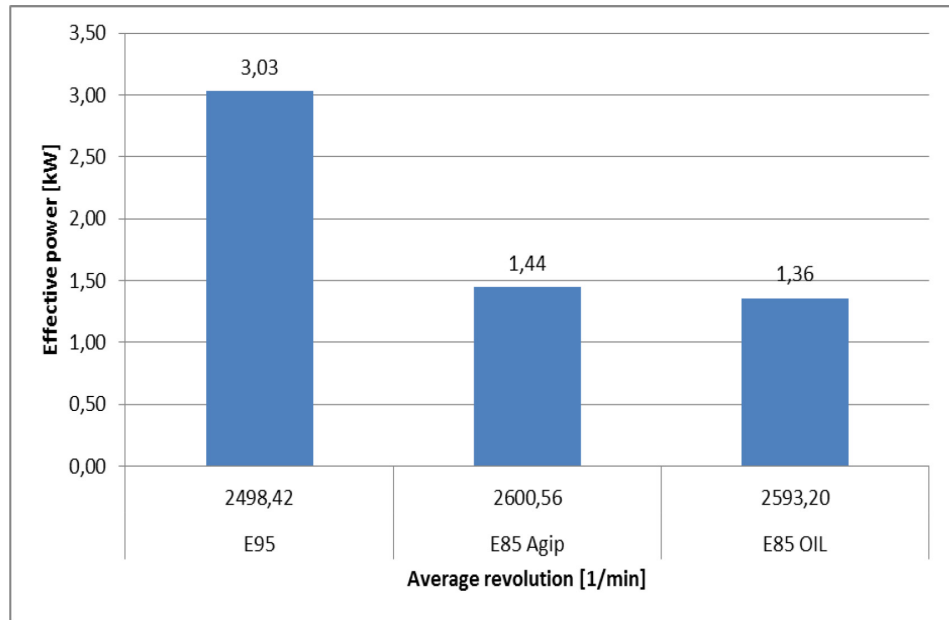

Figure 2. Connections between effective power and rpm.

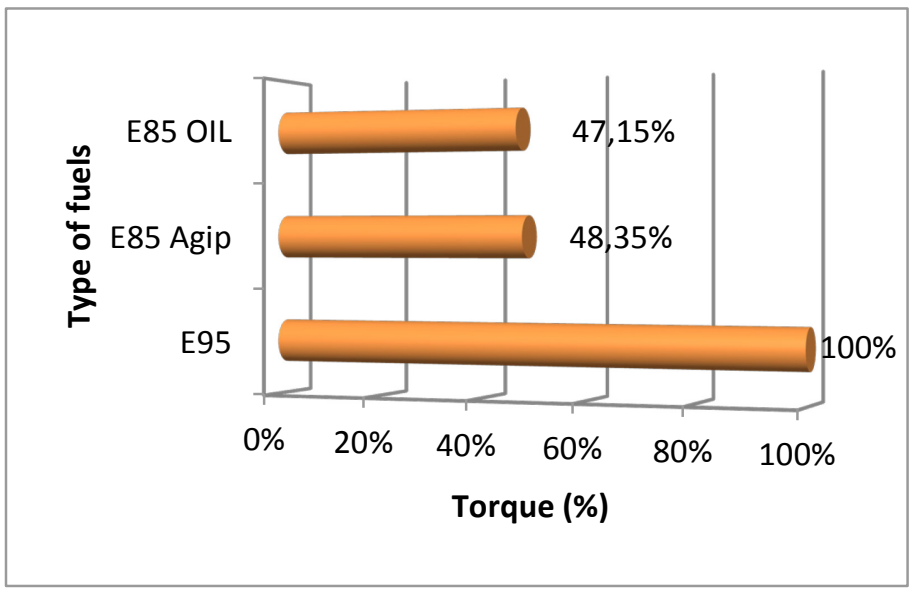

Figure 3. Changes between torque and fuel types 


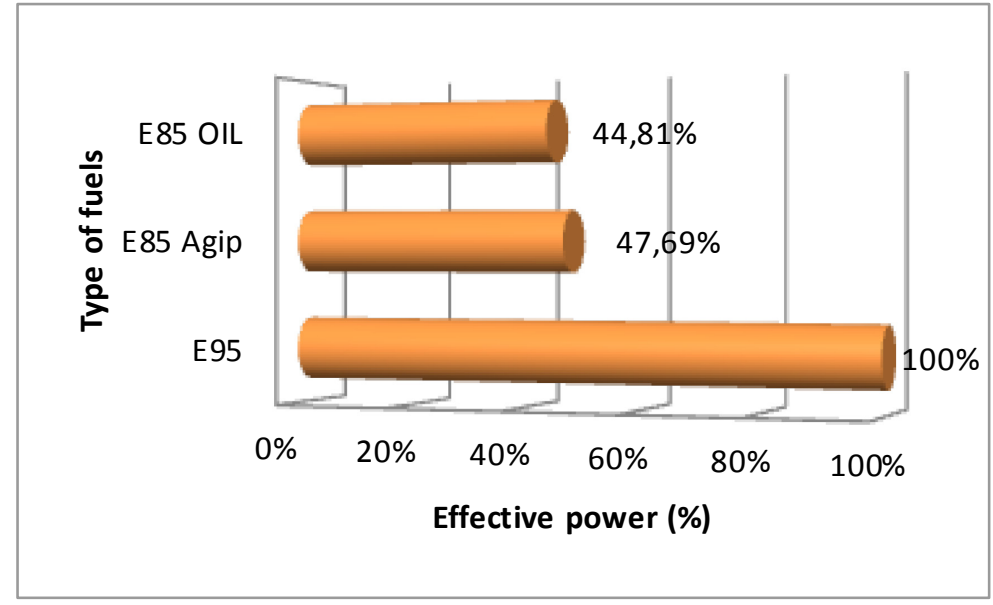

Figure 4. Changes between effective power and fuel types

\section{DISCUSSION}

For this project two different manufacturer's bioethanol fuels were assessed with regard to their combustion behaviours by unchanged settings. The tests were carried out at a Honda GX 160 engine equipped electric brake. We determined that large-scale deviations of calorific value and stoichiometric ratio caused the explored very smaller torque and effective power values (less, than $50 \%$ ) in case of bioethanols.

Certainly by engine settings changes (e.g. ignition timing adjustment, increasing compression ratio, spark plug) we can further improved behaviour of our engine.

\section{CONCLUSIONS}

Our three short-term tests were operated with commercial gasoline and two different bioethanol fuels (AGIP-E85, OIL-E85) with the aim to compare the IC engine behaviours by unchanged settings. We'd recognised more less, than $50 \%$ values in case of torque and effective power, which can explain with lower calorific value $(26.7 \mathrm{MJ} / \mathrm{kg})$ and stoichiometric ratio (8.97) of bioethanols.

We would like to continue our examinations testing several blending bioethanol fuels for further percentage distribution.

\section{REFERENCES}

[1] A. Demirbas, Progress and recent trends in biodiesel fuels, Energy Conversion and Management, 50, (2009), pp. 14-34

[2] A. Demirbas, I. Demirbas, Importance of rural bioenergy for developing countries. Energy Convers Manage, 48, (2007), pp. 2386-2398

[3] A. Bilgin, O. Durgun, Z. Sahin, The effects of diesel-ethanol blends on diesel engine performance. Energy Sources, 24, (2002), pp. 431-40

[4] K. Nagai, T. Seko, Trends of motor fuel quality in Japan. JSAE Rev., 21, (2000), pp. 457-462

[5] H. K. Speidel, R. L. Lightner, I. Ahmed, Biodegradability of new engineered fuels compared to conventional petroleum fuels and alternative fuels in currentuse. Appl Biochem Biotechnol, 84-86, (2000), pp. 879-897 
[6] Y. He, Y. D. Bao, Study on rapeseed oil as alternative fuel for a single-cylinder diesel engine. Renew Energy, 28, (2003), pp. 1447-1453

[7] http://www.fs-unep-centre.org

[8] World of Biofuels 2015

[9] Biofuels in transport in 2016 